\title{
Patient Enablement in Chronic Diseases in Primary Health Care, Riyadh City, KSA
}

\author{
Rabaa K. Al Momen, Mishal M. Alotaibi, Osama Abdelhay \\ Department of Family and Community Medicine, Prince Sultan Military Medical City, Riyadh, KSA \\ Email: rabaa_almomen@yahoo.com
}

Received 26 June 2015; accepted 7 September 2015; published 10 September 2015

Copyright (C) 2015 by authors and Scientific Research Publishing Inc.

This work is licensed under the Creative Commons Attribution International License (CC BY).

http://creativecommons.org/licenses/by/4.0/

(c) (i) Open Access

\section{Abstract}

Background: Chronic diseases continue to cause high morbidity and mortality in Saudi Arabia. Patients severing from diabetes mellitus, hypertension and associated complications have recently increased and most of these patients find it extremely difficult to understand or cope with their illness. The objective of this study is to determine the level of patients' enablement in chronic disease and its predictors. Methods: A community based cross-sectional study was conducted between December 2014 and January 2015. Six hundred and four (604) Patients attending the Chronic Disease Clinic in Alwazarat Health center were randomly selected to participate in the study. Patients aged 18 years and above, who willingly agreed to participate, were included in the study. Self-reported questionnaire was used to determine patient level of enablement. Descriptive statistics such as mean and median were calculated and binary logistic regression was employed to determine the predictors of patient's enablement to chronic disease. Results: Our results show that five hundred and sixty five (565) out of (604) patients participated in the study with $86.6 \%$ response rate. Type 2 diabetes mellitus affecting 40.65\% while hypertension affecting $37.79 \%$ of the patients in Al wazarat health center. Patient's enablement to chronic disease was very low and ranged between 2.41 and 1.53 out of 5.0. Binary logistic regression shows that age (male: OR; 0.84, 95\% CI, 0.72 - 1.04, female. OR; 1.04, 95\% CI 0.88 - 1.39), marital status (male: OR; 0.72, 95\% CI 0.54 - 1.11, female: OR 1.01; 95\% CI 0.82 - 1.29), patient educational level and number of problems discussed with physician and consultation length between male patients and their physician were statistically significant and correlated with patients enablement to chronic disease $(P<0.05)$. Conclusion: This study shows that patient's enablement in chronic disease is very low but constitutes an important arm in patients care management. It should be considered as a measurable patient outcome from healthcare services. More prospective studies on this important topic are highly recommended.

\section{Keywords}

Chronic Disease, Cross-Sectional, Logistic Regression, Enablement, Patient Assessment

How to cite this paper: Al Momen, R.K., Alotaibi, M.M. and Abdelhay, O. (2015) Patient Enablement in Chronic Diseases in Primary Health Care, Riyadh City, KSA. International Journal of Clinical Medicine, 6, 615-622. 


\section{Introduction}

The Global Burden of Disease and Injury study estimated that worldwide death due to chronic conditions is increasing and projected to rise up to about 70\% by 2020 [1]-[3]. In Saudi Arabia the improvement in the quality of healthcare provided has shifted and reduces death due to infection diseases with similar increase in the prevalence of death due to chronic conditions such as diabetic mellitus, hypertension and associated complications [4] [5]. Chronic diseases consume a lot of time and efforts from health professions and it is for the benefit of both parties that patients enablement is considered highly [6]. Unlink in acute illness, patient with chronic disease modify or adapt different behaviors than that prior to their chronic illness [7]. Their behavior depends largely on how they accept their illness and how the health care givers organize their services [4]. Although a lot of guidelines were published on the management of different chronic disease such as diabetes, hypertension and asthma but there is a gap in the effective patient involvement of their own problems [8].

It has been shown that in many studies patients enablement plays very significant part in treatment of chronic conditions [9] [10]. Patient enablement is defined as the extent to which a patient is capable of understanding and coping with his or her health issues [11]. The concept of enablement was further focused in the general practice setting, to the extent of the patient's own feelings of enablement about his/her condition after the medical consultation [12]. In general practice, the doctor patient consultation is a situation where different issues concerning patient health are encountered [13]. In many occasions the patients' understanding, capability of coping with their illness and taking care of themselves are all left un-defined in the hand of the medical service provider [14]. Patients present to the primary care settings for various reasons, some of them come for acute short trivial problems, and others may come frequently for long standing chronic diseases [2] [15]. Health promotion definition was changing over the years to embrace the process of enabling people to increase control over their health and its determinants, and thereby improve their health (Michael P. O'Donnell, 2009) [16]. It is expected that health promotion is one of the important part of all these consultation with special considerations to chronic diseases [17]. The more enabled the patients about understanding their illness, the better the outcome for both patients and the healthcare providers.

This study's objective is to assess the level of patients' enablement in primary care chronic disease clinics and determine its main predictors.

\section{Methods}

\subsection{Study Design}

An observational cross-sectional study was carried out in Al wazarat Health Center in Riyadh between December 2014 and January 2015.

\subsection{Study Area and Population}

$\mathrm{Al}$ Wazarat health center is located in the Middle of Riyadh city. It runs many clinics such chronic disease clinic which provides primary care services to Riyadh military personnel, civil employed personnel in the military organizations and their dependents. Adult patients aged above 18 years with history of chronic illness such as diabetes, hypertension and bronchial asthma who willingly agree to participate in the study were included. Only patients who have been seen in the center for more than 6month were allowed to participate in the study. Patients who did not consented to participate in the study and those with who were severely ill were excluded from the study.

\subsection{Sample Size and Sampling Method}

A sample size of 669 was calculated using Epi Info 2000 (ATLANTIS 2004) [18]. A convenient sampling method was adapted because chronic disease patients may lack interest to participate in studies due to their chronic conditions.

\subsection{Study Variables}

The study variables were divided into dependent or outcome variable such as patient chronic disease enablement while the independent variables were the socio-demographic characteristics such age, gender, marital status and 
income, employment status and educational level.

\subsection{Study Instrument (Questionnaire)}

The questionnaire was developed by authors form literature and experts from the department of family and community medicine department. The questions used are close ended in the Yes and No format. It consisted of part one which contain the socio-demographic characteristics and part two had questions about patient's enablement and chronic diseases such as diabetes Miletus, hypertension, hypothyroidism and asthma. It was pre-tested on 20 participants with different educational level, validated and then translated into Arabic language by two translators.

\subsection{Data Collection}

Data was collected using self-reported questionnaire by a train research assistant. It was administered to participants who satisfied the inclusion criteria stated above. All privacy and confidentiality were maintained.

\subsection{Data Entry and Analysis}

Collected data was entered into SPSS version 18 for windows by research assistant [19]. Six hundred and four patients were approached for the study (604), and five hundred and sixty five (565) participated in the study. Forty one study instruments were found to have incomplete data and were removed, the remaining 524 instrument were analyzed. Initial descriptive analysis included frequency, mean and median and percentages were carried out. Binary logistic regression was used to predict the association between variables. The dependent variable was enablement score and socio-demographic characteristics were independent variables.

Ethical approval was obtained before the start of the study. Patient's confidentiality and privacy were maintained throughout the study period.

\section{Results}

Of the 604 study participants 524 returned completed study questionnaire given a response rate of $86.6 \%$. Majority of the participants were male (58.8\%) and the remaining $41.2 \%$ were female. Participants with age group greater than 42 years of age were $45.9 \%$ as compared to $0.6 \%$ for participants aged between 18 and 25 years. Most of the participants had one form of education or other (89.7\%) while only $10.3 \%$ were illiterate. Almost two third of the participants $65.1 \%$ were employed while the remaining $34.9 \%$ were unemployed. Table 1 shows the details of socio-demographic characteristics as described above. Majority of patients had Diabetes Milieus (213, 40.65\%), followed by hypertension (198, 37.79\%) while hypothyroidism was the disease with the least prevalence rate of $(16,3.05 \%)$ as shown in (Table 2). The highest incidence rate was 0.41 for DM compared with 0.03 for hypothyroidism.

Table 3 shows the results of patient's median enablement scores for some socio-demographic characteristics and consultations parameters. Median enablement score for male participants was 2.39 as compared to 2.03 for females. Out of the total 524 participants 203 or $38.7 \%$ knew their doctors very well and had a median enablement score of 2.41 . One hundred and eleven or $21.2 \%$ of the participants knew their doctors well with median enablement score of 2.30. The lest median enablement score was 1.63 for the participants who did not know their doctors at all. Participants who discussed one problem with their doctors had highest median enablement score of 2.38 as compared to lowest median enablement score of 1.53 for the participants who discussed more than three problems with their doctors. Patients with consultations time of 12 to 17 minutes had higher median enablement score of 2.31 as compared to a lower median score of 1.82 for those who spent less than five minutes with their doctors.

Binary logistic regressions model was utilized t to predict the association between patient enablement to chronic disease (Dependent variable) and socio-demographic characteristics and patients consultations character as (independent variables). Patient educational level number of problems (related to their chronic disease) discussed with their physician and consultation length was statistically significant (Table 4) while patients age, marital status, employment status and patients knowledge of their physician were not statistically significant.

Table 4 describes the results of patients enablement in chronic disease as associated with their corresponding show demographic characteristics. Patients' age and marital status were found to be statistically insignificant 
with p value of 0.315 and 0.084 respectively. Patient educational level for male and female participants was found to be statistically significant with p vale of 0.021 and 0.001 respectively. Patient consultation length has been found to be statistically associated with their enablement score level with a p value of 0.048 . Number of problems discussed between patients and their doctors during consultation was also found to be statistically significant with their median enablement score with a p value of 0.002 and 0.004 for males and females participants.

\begin{tabular}{|c|c|c|}
\hline Variable & $\mathrm{N}$ & $\%$ \\
\hline \multicolumn{3}{|l|}{ Gender } \\
\hline Female & 216 & 41.2 \\
\hline Male & 308 & 58.8 \\
\hline Total & 524 & 100 \\
\hline \multicolumn{3}{|l|}{ Age (Years) } \\
\hline $18-25$ & 034 & 06.49 \\
\hline $26-33$ & 092 & 17.56 \\
\hline $34-41$ & 156 & 29.77 \\
\hline$>42$ & 242 & 45.92 \\
\hline Total & 524 & 100 \\
\hline \multicolumn{3}{|l|}{ Marital status } \\
\hline Married & 293 & 55.92 \\
\hline Single & 58 & 11.07 \\
\hline Divorced & 127 & 24.24 \\
\hline Widow & 29 & 5.54 \\
\hline Widower & 17 & 3.24 \\
\hline Total & 524 & 100 \\
\hline \multicolumn{3}{|l|}{ Education level } \\
\hline No formal schooling & 54 & 10.31 \\
\hline Primary school & 148 & 28.24 \\
\hline Secondary school & 169 & 32.25 \\
\hline University & 134 & 25.57 \\
\hline Postgraduate & 19 & 3.63 \\
\hline Total & 524 & 100 \\
\hline \multicolumn{3}{|l|}{ Employment Status } \\
\hline Not employed & 183 & 34.92 \\
\hline Employed & 341 & 65.08 \\
\hline Total & 146 & 100 \\
\hline
\end{tabular}


Table 2. Types of chronic disease and number of patients in follow up with Chronic Diseases Clinic in Wazarat Family Medicine Center $(\mathrm{n}=524)$.

\begin{tabular}{ccccc}
\hline Chronic Disease & Patient Number (N) & Percentage (\%) & Prevalence Rate & 95\% Confidence Interval \\
\hline Diabetes Mellitus & 213 & 40.65 & 0.4065 & $0.3537-0.4649$ \\
Hypertension & 198 & 37.79 & 0.3779 & $0.3271-0.4343$ \\
Bronchial Asthma & 42 & 8.02 & 0.08015 & $0.05777-0.10834$ \\
hypothyroidism & 16 & 3.05 & 0.03053 & $0.01745-0.0495955$ \\
Other chronic illness & 55 & 10.50 & 0.105 & $0.0791-0.1366$ \\
Total & 524 & 100 & &
\end{tabular}

Table 3. Consultation parameters and calculated patients enablement score $(n=524)$.

\begin{tabular}{|c|c|c|c|}
\hline & Patient No & Percentage (\%) & Median Enablement Score \\
\hline \multicolumn{4}{|l|}{ Gender } \\
\hline Female & 216 & 41.2 & 2.03 \\
\hline Male & 308 & 58.8 & 2.39 \\
\hline Total & 524 & 100 & \\
\hline \multicolumn{4}{|c|}{ Patients level of knowing the doctor } \\
\hline Very well & 203 & 38.7 & 2.41 \\
\hline Well & 111 & 21.2 & 2.30 \\
\hline Fairly well & 86 & 16.4 & 1.99 \\
\hline Not at all & 124 & 23.7 & 1.63 \\
\hline Total & 524 & 100 & \\
\hline \multicolumn{4}{|c|}{ No of problems discussed by participants } \\
\hline 1 & 128 & 24.5 & 2.38 \\
\hline $2-3$ & 349 & 66.6 & 2.1 \\
\hline$>3$ & 47 & 8.9 & 1.53 \\
\hline Total & 524 & 100 & \\
\hline \multicolumn{4}{|c|}{ Length of consultation (minutes) } \\
\hline $0-5$ & 58 & 11.1 & 1.82 \\
\hline $6-11$ & 259 & 49.4 & 1.93 \\
\hline $12-17$ & 122 & 23.3 & 2.31 \\
\hline$>17$ & 85 & 16.2 & 1.73 \\
\hline Total & 524 & 100 & \\
\hline
\end{tabular}


Table 4. Association between Patient Enablement in chronic disease and Patients socio-demographic and consultation characters.

\begin{tabular}{ccccc}
\hline Predictor & Male (Odds ratio with 95\% CI) & $\mathrm{p}$ & Female (Odds ratio with 95\% CI) & $\mathrm{p}$ \\
\hline Age & $0.84(0.72-1.04)$ & 0.435 & $1.04(0.88-1.39)$ & 0.315 \\
Education & $1.25(1.02-1.83)$ & $0.021^{*}$ & $1.18(0.93-1.25)$ & $0.001^{*}$ \\
Marital status & $0.72(0.54-1.11)$ & 0.712 & $1.01(0.82-1.29)$ & 0.084 \\
Consultation length & $0.99(0.83-1.29)$ & $0.048^{*}$ & $0.92(0.87-1.01)$ & 0.223 \\
$\begin{array}{c}\text { Knowing the Physician } \\
\text { No of Problems discussed } \\
\text { with the physician }\end{array}$ & $1.00(0.99-1.07)$ & 0.062 & $1.03(1.00-1.28)$ & 0.082 \\
Employment status & $0.86(0.74-1.05)$ & $0.002^{*}$ & $0.98(0.75-1.02)$ & $0.004^{*}$ \\
\hline
\end{tabular}

" -value less than 0.05 is considered statistically significant.

\section{Discussion}

Patients enablement which is about patients ability to understand their sickness and cope with it, in clinical practice generally depend on two important elements namely "holism" which, is an approach to construction of diagnoses and patient-centered care which is defined as the use of adequate consulting skills in identifying patients' priorities and concerns and the appropriate involvement of patients in making decisions about their care.

This study found that the average total chronic disease patient's enablement score was very low and ranged between 2.41 and 1.53 out of 5.0, these values can also be compared to similar finding by John GR and colleges who found an enablement score of about $44.1 \%$ [20].

Male participants had high enablement compared to their female counterpart in the study. Patients who knew their doctors before consultation were also more enabled compared to those who did not know their doctors before consultation. Patient's enablement was found to be affected by the consultation language, consultation time, number of problems discussed between the patients and their physician and ethnic differences [21]-[23]. In our study Arabic language was the main consultation language and the embalmment score was lower (2.41) when compared with other similar studies in UK, USA and Poland. Patients enablement was higher in similar study in UK (3.1) and (3.6) in Poland [24]. It is important however to put the educational level of patient and their culture into consideration when comparing patients chronic disease enablement in Saudi Arabia with their counterpart in UK and USA. Saudi Arabia is conservative society as compared to other western countries like UK, this significantly affecting patient's doctor relationship and is clearly reflected in low patient's enablement. Patients in UK tend to be more aware of their treatment right during consultation and as such engaged more freely with their health care provider than in our study [25].

The median score for patient enablement was found to be between 2.41 to 1.53 . It was clearly affected by patient's doctor relationship, length of consultation and number problems discussed by the patients with his physician. Patients who knew his physician very well had the highest enablement score compared to those who did not knew their physician at all, this result was similar to study conducted by other researcher [26]. Those who had average consultation time of 12 - 17 minutes same to have the highest enablement score $(12-17,2.31)$ compared to those with short consultation time of $(0-5,1.82)$. From Table 4 above it is also obvious that the number of problems discussed by patients with their physician also significantly affected the patient chronic disease enablement.

Our findings are important and can be utilized to improve the healthcare services provided to patients with chronic diseases in Saudi Arabia and the gulf region as well. Improving patient's enablement level will help them to understand and coup more effectively with their chronic disease.

The study findings just like other studies have some limitations which may have affected our results. We have improved the language, contents and design of our study instruments in order to overcome the recall bias. The generalizability of this study may be limited to $\mathrm{Al}$ Wazarat health center and other primary care health center as the authors could not conduct a multi-center study due to limitation of resources. The clinical and practical value 
of this study is very important to doctors as findings could be utilized for managing future patients with similar chronic disease in Al Wazarat center and other primary health care settings. From the findings patients' consultation time, number of problems to be discussed during consultations and patients doctors' relationship should be highly considered. Patient's clinical outcome depends mainly on their full enablement in discussing their health problems freely with their doctors within a sufficient consultation time and concentration on only one or two health important problems affecting their health.

In conclusion this is one of the first studies to discuss in details patients enablement to chronic disease in the Kingdom of Saudi Arabia. Our findings are important and can be utilized to improve the healthcare services provided to patients with chronic diseases in Saudi Arabia and the gulf region as well. Improving patient's enablement level will help them to understand and cope more effectively with their chronic disease.

\section{Acknowledgements}

Authors gratefully acknowledged the research assistant and all staff who provided any form of assistant during the study period. More importantly thanks goes to the participants for their contributions.

\section{Author's Contribution}

Rabaa K Al Momen is the principle investigator, wrote the article and provided essential logistic for the study while Mishaal A and Osama A wrote the study proposal, contributed equally in data collection, analysis and interpretation. All authors read, edited and agreed to the manuscript before submission for publication.

\section{Conflict of Interest}

Authors have no conflict of interest to declare.

\section{References}

[1] Murray, C.J. and Lopez, A.D. (1997) Alternative Projections of Mortality and Disability by Cause 1990-2020: Global Burden of Disease Study. The Lancet, 349, 1498-1504. http://dx.doi.org/10.1016/S0140-6736(96)07492-2

[2] Mathers, C.D. and Loncar, D. (2006) Projections of Global Mortality and Burden of Disease from 2002 to 2030. PLoS Medicine, 3, e442. http://dx.doi.org/10.1371/journal.pmed.0030442

[3] Gensichen, J., Serras, A., Paulitsch, M., Rosemann, T., König, J., Gerlach, F. and Petersen, J. (2011) The Patient Assessment of Chronic Illness Care Questionnaire: Evaluation in Patients with Mental Disorders in Primary Care. Community Mental Health Journal, 47, 447-453. http://dx.doi.org/10.1007/s10597-010-9340-2

[4] Hanan, A.-A. and Roland, M. (2005) Quality of Primary Health Care in Saudi Arabia: A Comprehensive Review. International Journal for Quality in Health Care, 17, 331-346. http://dx.doi.org/10.1093/intqhc/mzi046

[5] Whiting, D.R., Guariguata, L., Weil, C. and Shaw, J. (2011) IDF Diabetes Atlas: Global Estimates of the Prevalence of Diabetes for 2011 and 2030. Diabetes Research and Clinical Practice, 94, 311-321.

[6] Wensing, M., van Lieshout, J., Jung, H.P., Hermsen, J. and Rosemann, T. (2008) The Patients Assessment Chronic Illness Care (PACIC) Questionnaire in The Netherlands: A Validation Study in Rural General Practice. BMC Health Services Research, 8, 182.

[7] Novalis, P.N., Rojcewicz, S.J. and Peele, R. (1993) Clinical Manual of Supportive Psychotherapy. American Psychiatric Publishing.

[8] Brusse, C.J. and Yen, L.E. (2013) Preferences, Predictions and Patient Enablement: A Preliminary Study. BMC Family Practice, 14, 116. http://dx.doi.org/10.1186/1471-2296-14-116

[9] Rogers, A., Kennedy, A., Nelson, E. and Robinson, A. (2005) Uncovering the Limits of Patient-Centeredness: Implementing a Self-Management Trial for Chronic Illness. Qualitative Health Research, 15, 224-239. http://dx.doi.org/10.1177/1049732304272048

[10] Shaw, A., Ibrahim, S., Reid, F., Ussher, M. and Rowlands, G. (2009) Patients' Perspectives of the Doctor-Patient Relationship and Information Giving across a Range of Literacy Levels. Patient Education and Counseling, 75, 114-120. http://dx.doi.org/10.1016/j.pec.2008.09.026

[11] Andén, A., Andersson, S.-O. and Rudebeck, C.-E. (2009) To Make a Difference-How GPs Conceive Consultation Outcomes. A Phenomenographic Study. BMC Family Practice, 10, 4. http://dx.doi.org/10.1186/1471-2296-10-4

[12] Rööst, M., Zielinski, A., Petersson, C. and Strandberg, E.L. (2015) Reliability and Applicability of the Patient Enablement Instrument (PEI) in a Swedish General Practice Setting. BMC Family Practice, 16, 31. 
http://dx.doi.org/10.1186/s12875-015-0242-9

[13] Kaplan, S.H., Greenfield, S. and Ware Jr., J.E. (1989) Assessing the Effects of Physician-Patient Interactions on the Outcomes of Chronic Disease. Medical Care, 27, S110-S127. http://dx.doi.org/10.1097/00005650-198903001-00010

[14] Kurosawa, S., Matsushima, M., Fujinuma, Y., Hayashi, D., Noro, I., Kanaya, T., Watanabe, T., Tominaga, T., Nagata, T. and Kawasaki, A. (2012) Two Principal Components, Coping and Independence, Comprise Patient Enablement in Japan: Cross Sectional Study in Tohoku Area. The Tohoku Journal of Experimental Medicine, 227, 97-104. http://dx.doi.org/10.1620/tjem.227.97

[15] Glasgow, R.E., Wagner, E.H., Schaefer, J., Mahoney, L.D., Reid, R.J. and Greene, S.M. (2005) Development and Validation of the Patient Assessment of Chronic Illness Care (PACIC). Medical Care, 43, 436-444. http://dx.doi.org/10.1097/01.mlr.0000160375.47920.8c

[16] O’Donnell, M.P. (2009) Definition of Health Promotion 2.0: Embracing Passion, Enhancing Motivation, Recognizing Dynamic Balance, and Creating Opportunities. American Journal of Health Promotion, 24, 4. http://dx.doi.org/10.4278/ajhp.24.1.iv

[17] Sprangers, M.A. and Aaronson, N.K. (1992) The Role of Health Care Providers and Significant Others in Evaluating the Quality of Life of Patients with Chronic Disease: A Review. Journal of Clinical Epidemiology, 45, 743-760. http://dx.doi.org/10.1016/0895-4356(92)90052-0

[18] Atlantis, T. (2004) Association of Outcome with Early Stroke Treatment: Pooled Analysis of ATLANTIS, ECASS, and NINDS rt-PA Stroke Trials. The Lancet, 363, 768-774. http://dx.doi.org/10.1016/S0140-6736(04)15692-4

[19] Carver, R. and Nash, J. (2011) Doing Data Analysis with SPSS: Version 18.0. Cengage Learning, Belmont.

[20] Howie, J., Heaney, D.J., Maxwell, M. and Walker, J.J. (1998) A Comparison of a Patient Enablement Instrument (PEI) against Two Established Satisfaction Scales as an Outcome Measure of Primary Care Consultations. Family Practice, 15, 165-171. http://dx.doi.org/10.1093/fampra/15.2.165

[21] Howie, J.G., Heaney, D.J., Maxwell, M., Walker, J.J., Freeman, G.K. and Rai, H. (1999) Quality at General Practice Consultations: Cross Sectional Survey. BMJ, 319, 738-743. http://dx.doi.org/10.1136/bmj.319.7212.738

[22] McKinstry, B., Walker, J., Blaney, D., Heaney, D. and Begg, D. (2004) Do Patients and Expert Doctors Agree on the Assessment of Consultation Skills? A Comparison of Two Patient Consultation Assessment Scales with the Video Component of the MRCGP. Family Practice, 21, 75-80. http://dx.doi.org/10.1093/fampra/cmh116

[23] Adžić, Z.O., Katić, M., Kern, J., Lazić, Đ., Nekić, V.C. and Soldo, D. (2008) Patient, Physician, and Practice Characteristics Related to Patient Enablement in General Practice in Croatia: Cross-Sectional Survey Study. Croatian Medical Journal, 49, 813-823. http://dx.doi.org/10.3325/cmj.2008.49.813

[24] Pawlikowska, T., Nowak, P., Szumilo-Grzesik, W. and Walker, J. (2002) Primary Care Reform: A Pilot Study to Test the Evaluative Potential of the Patient Enablement Instrument in Poland. Family Practice, 19, 197-201. http://dx.doi.org/10.1093/fampra/19.2.197

[25] Howie, J.G., Heaney, D.J., Maxwell, M., Walker, J.J. and Freeman, G.K. (2000) Developing a "Consultation Quality Index” (CQI) for Use in General Practice. Family Practice, 17, 455-461. http://dx.doi.org/10.1093/fampra/17.6.455

[26] Gray, D.P., Evans, P., Sweeney, K., Lings, P., Seamark, D., Seamark, C., Dixon, M. and Bradley, N. (2003) Towards a Theory of Continuity of Care. Journal of the Royal Society of Medicine, 96, 160-166. http://dx.doi.org/10.1258/jrsm.96.4.160 